\title{
COMPOSIÇÃO QUÍMICA E ATIVIDADE BIOLÓGICA DE EXTRATO OLEOSO DE PRÓPOLIS: UMA ALTERNATIVA AO EXTRATO ETANÓLICO
}

\author{
Lilian Buriol, Daiane Finger, Eduardo Morgado Schmidt, Julio M. T. dos Santos, Marcos Roberto da Rosa, Sueli Pércio \\ Quináia e Yohandra Reyes Torres* \\ Departamento de Química, Centro de Desenvolvimento Educacional e Tecnológico de Guarapuava, Universidade Estadual do
} Centro-Oeste, R. Simeão Camargo Varela de Sá, 3, 85040-080 Guarapuava - PR, Brasil

Herta Stutz Dalla Santa

Departamento de Engenharia de Alimentos, Centro de Desenvolvimento Educacional e Tecnológico de Guarapuava, Universidade Estadual do Centro-Oeste, R. Simeão Camargo Varela de Sá, 3, 85040-080 Guarapuava - PR, Brasil

Cláudia Pessoa, Manoel Odorico de Moraes, Letícia Veras Costa-Lotufo e Paulo Michel Pinheiro Ferreira

Departamento de Fisiologia e Farmacologia, Universidade Federal do Ceará, R. Coronel Nunes de Melo, 1127, 60431-970

Fortaleza - CE, Brasil

Alexandra Christine Helena Frankland Sawaya e Marcos Nogueira Eberlin

Instituto de Química, Unicamp, Campinas - SP, Brasil

Recebido em 19/12/07; aceito em 2/9/08; publicado na web em 2/2/09

\begin{abstract}
CHEMICAL COMPOSITION AND BIOLOGICAL ACTIVITY OF OIL PROPOLIS EXTRACT: AN ALTERNATIVE TO ETHANOLIC EXTRACT. Propolis is mostly used as hydroalcoholic extract. Recently there has been a growing number of patents dealing with new solvents for preparing propolis extracts. This study aimed to prepare edible oil propolis extracts and compare their chemical composition and biological activity with ethanolic propolis extracts. ESI-MS and spectrophotometric methods were used for qualitative and quantitative analyses, respectively. Antibacterial activity was evaluated by diffusion in agar. Cytotoxicity was tested by MTT assay using tumor cell lines. The oil is able to extract bioactive compounds from propolis. Further studies are needed to improve extraction efficiency and to characterize the active components.
\end{abstract}

Keywords: oil propolis extract; phenolic compounds; antibacterial and cytotoxic activities.

\section{INTRODUÇÃO}

A própolis é uma resina de ampla utilidade para as abelhas e para o homem. ${ }^{1,2}$ A composição química da própolis é complexa e está relacionada com a flora da região em que foi originada e a época da coleta. ${ }^{3-6}$ Sua atividade farmacológica tem sido atribuída aos compostos fenólicos, entre eles flavonóides e ácidos fenólicos, cujos teores têm sido propostos como parâmetros para o controle da qualidade. ${ }^{7,8}$ Devido às inúmeras propriedades benéficas da própolis, $\mathrm{o}$ seu uso comercial em produtos farmacêuticos, cosméticos e de higiene pessoal na forma de extratos líquidos é amplo. Para a elaboração desses produtos, é comumente utilizado o extrato obtido com álcool de cereais $70 \%$ v/v e tempos de extração que variam de 1 dia até 6 meses. ${ }^{9}$ Entretanto, a presença de álcool na formulação confere um sabor não agradável para alguns consumidores.

Buscando superar esses inconvenientes, têm surgido muitas patentes que propõem novos métodos de extração da própolis com baixo teor alcoólico ou isento de álcool. ${ }^{10-15}$ Dentre as alternativas propostas, destaca-se o extrato de própolis obtido com óleo vegetal, o qual conserva bem as características organolépticas da própolis e possibilita a apresentação do produto em cápsulas gelatinosas. Existe uma dúvida, porém, quanto à eficiência do óleo comestível em extrair os principais compostos bioativos da própolis e se os produtos elaborados com o extrato oleoso possuem ou não as propriedades farmacológicas adequadas para a finalidade à qual são destinados.

Neste trabalho avaliamos o extrato oleoso de própolis quanto

*e-mail: ryohandra@yahoo.com a sua composição química qualitativa e quantitativa de compostos fenólicos extraídos e comparamos os resultados com aqueles obtidos de diferentes extratos etanólicos de própolis. Este estudo empregou as técnicas de espectrometria de massas com ionização por electrospray (ESI-MS) e espectrofotometria no UV-VIS. Como as atividades antibacteriana e citotóxica de extratos hidroalcoólicos e de alguns compostos isolados de própolis são bem conhecidas, ${ }^{2}$ procurou-se avaliar se o extrato oleoso também possuía essas atividades. Neste trabalho o extrato oleoso da própolis foi, então, avaliado in vitro em diferentes cepas de organismos patogênicos e em linhagens de células tumorais humanas para estimar suas atividades antibacteriana e citotóxica, respectivamente. Com os dados obtidos, foi feita a análise das componentes principais (ACP) para melhor comparar os extratos hidroalcoólicos e oleosos de própolis quanto aos teores de substâncias fenólicas e rendimentos de extração.

\section{Espectrometria de massas com ionização por electrospray na análise de misturas complexas}

Muitos trabalhos relatam a análise qualitativa e quantitativa dos constituintes químicos da própolis através de cromatografia gasosa acoplada à espectrometria de massas (CG-EM $)^{6,16-19}$ e por cromatografia líquida de alta eficiência (CLAE). ${ }^{5,6,19-21}$

Como os componentes da própolis são na sua maioria compostos fenólicos, ácidos carboxílicos e seus derivados, os mesmos podem ser desprotonados em soluções básicas e analisados por ESI(-)-MS, como demonstrado por Sawaya et al...$^{22,23}$ Esses pesquisadores aplicaram ESI (-)-MS para analisar amostras de própolis vermelha, verde e marrom de 
diversas regiões do Brasil. ESI(-)-MS mostrou ser uma técnica analítica rápida e confiável para análise direta de extratos hidroalcoólicos de própolis, possibilitando a classificação da própolis brasileira em grupos, de acordo com íons marcadores observados nos espectros. Estes íons são característicos e indicam a origem regional da própolis testada. ${ }^{22-24}$

ESI-MS tem sido aplicada também à análise de outras misturas complexas como vinho, petróleo, cerveja e extratos de fontes naturais. ${ }^{25-29}$ De maneira geral, moléculas de baixa massa molecular (<1000 Da), contendo poucos sítios ácidos ou básicos, produzem espectros de massas simples por ESI, onde um único íon correspondente a sua forma desprotonada (M-H) ou protonada $(\mathrm{M}+\mathrm{H})^{+}$é detectado. Uma análise estrutural mais detalhada da composição química dos extratos pode ser auxiliada com o uso de amostras autênticas ou através da espectrometria de massas seqüencial MS/MS..$^{30,31}$

\section{Determinação de fenólicos totais e flavonóides}

Os compostos fenólicos presentes nas plantas, como flavonóides e ácidos fenólicos, têm sido muito estudados por suas propriedades antioxidantes. ${ }^{32,33}$ Os principais métodos utilizados na sua quantificação são a CLAE e a espectrofotometria no visível empregando o reagente de Folin-Ciocalteau. ${ }^{34}$ Este último método tem sido aplicado na determinação de fenólicos totais em sucos de uva, ${ }^{35}$ pitanga,${ }^{36}$ extrato aquoso de broto de feijão, ${ }^{37}$ plantas medicinais ${ }^{33}$ e própolis. ${ }^{6,8,38}$

A determinação de flavonóides sem a interferência dos outros compostos fenólicos pode ser realizada também pelo método espectrofotométrico após complexação com cloreto de alumínio. O cátion $\mathrm{Al}^{3+}$ forma complexos estáveis com os flavonóides em metanol, ocorrendo um desvio batocrômico do máximo de absorção. No entanto, como indicado por vários pesquisadores, ${ }^{8,39}$ deve-se considerar que o método produz valores inferiores aos reais, uma vez que as várias classes de flavonóides apresentam variações de absorção na região do comprimento de onda escolhido para análise.

\section{PARTE EXPERIMENTAL}

\section{Materiais e equipamentos}

As amostras de própolis analisadas foram cedidas pela empresa Campolin \& Schmidt de Prudentópolis/PR e coletadas em 2005. A própolis foi conservada em freezer até o momento da extração. Os solventes utilizados na extração da própolis e nas medidas de absorção no visível foram grau PA e grau espectrofotométrico, respectivamente. A água utilizada nas análises por UV-VIS, ESI-MS e na preparação de todas as soluções foi ultrapura destilada e deionizada (Human UP $900^{\circledR}$ ). O óleo de canola foi adquirido no mercado. Os reagentes empregados na determinação dos teores de fenólicos e flavonóides foram o Folin-Ciocalteau e o cloreto de alumínio da marca Biotec, o ácido gálico Vetec e a quercetina da Fischer.

As medidas de absorção foram feitas utilizando-se de espectrofotômetro Varian 50 BIO, no comprimento de onda fixo selecionado para determinação de fenólicos totais (700 nm) ou flavonóides (425 nm). Os espectros de massas foram obtidos em espectrômetro de massas Q-Trap da Applied Biosystems. As amostras foram analisadas por inserção direta no espectrômetro de massas com ionização por eletrospray em modo negativo. A voltagem do capilar foi ajustada a $-3000 \mathrm{~V}$ e a do cone em $50 \mathrm{~V}$ com uma temperatura de dessolvatação de $100{ }^{\circ} \mathrm{C}$.

\section{Análise qualitativa de extrato hidroalcoólico e oleoso de própolis por ESI(-)-MS}

A comparação da composição química dos extratos oleoso e hidroalcoólico de própolis por ESI(-)-MS foi realizada após a ex- tração por maceração e agitação magnética por 24 h, utilizando-se como solvente extrator etanol $95 \%$ v/v ou óleo de canola. Após esse período, as soluções extrativas foram filtradas a vácuo e armazenadas em geladeira.

Foram analisadas três amostras por ESI(-)-MS - amostra 1: óleo de canola puro, utilizado como referência para o extrato oleoso; amostra 2: extrato oleoso de própolis obtido com óleo de canola; amostra 3: extrato etanólico de própolis obtido com etanol 95\% v/v.

As amostras 2 e 3 e o padrão de referência oleoso 1 foram tratadas como exemplificado na Figura 1.

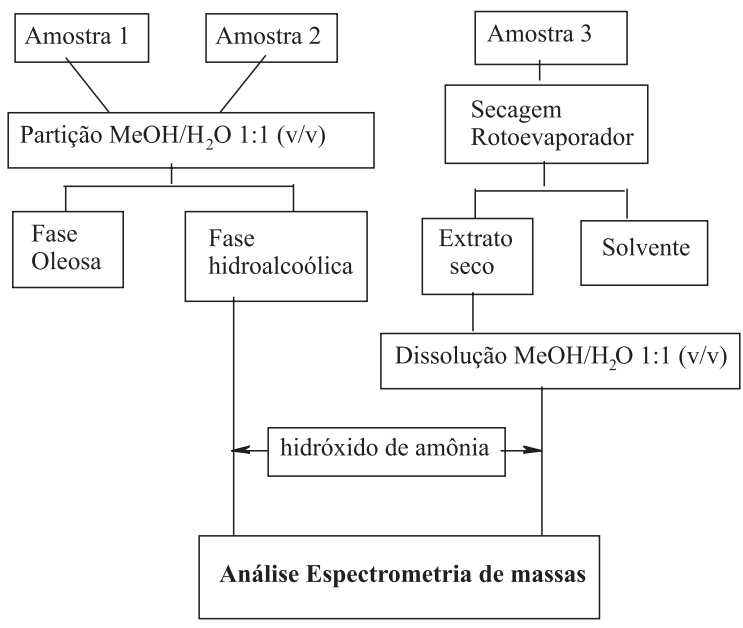

Figura 1. Preparo das amostras para análise por ESI(-)-MS

\section{Preparo dos extratos hidroalcoólicos de própolis}

Amostras contendo $5 \mathrm{~g}$ de própolis triturada foram extraídas com $25 \mathrm{~mL}$ de soluções etanólicas (30, 50, 70, 80, 95\% v/v e etanol absoluto) durante 10 dias, a temperatura ambiente e com agitação ocasional. Após esse período, filtrou-se e o filtrado foi deixado em repouso durante uma noite no freezer para precipitação e separação das ceras. O filtrado livre de ceras foi seco em evaporador rotativo e pesado, obtendo-se a massa dos extratos hidroalcoólicos secos de própolis.

\section{Preparo dos extratos oleosos de própolis}

O extrato oleoso foi obtido a partir de $5 \mathrm{~g}$ de própolis triturada com $25 \mathrm{~mL}$ de óleo de canola, a temperatura ambiente, e com agitação continua durante 10, 30 e 90 dias. Após o período de extração estabelecido, filtrou-se a vácuo com papel de filtro Whatman faixa preta quantitativo e o filtrado foi particionado com metanol/ $\mathrm{H}_{2} \mathrm{O}$ 8:2. A fase metanólica foi mantida em freezer por uma noite para precipitação das ceras. Após separação das ceras por filtração, a fase metanólica foi seca em evaporador rotativo a pressão reduzida. O resíduo obtido foi pesado obtendo-se assim a massa do extrato oleoso de própolis.

\section{Quantificação de fenólicos totais}

Primeiramente foi construída uma curva analítica usando-se soluções metanólicas padrão de ácido gálico em concentrações entre 1 a $165 \mu \mathrm{g} / \mathrm{mL}$. Em balão volumétrico de $5 \mathrm{~mL}$ misturaram-se 125 $\mu \mathrm{L}$ de cada solução padrão com $500 \mu \mathrm{L}$ de uma solução tampão de carbonato e tartarato de sódio e potássio e $500 \mu \mathrm{L}$ do reagente FolinCiocalteau. Ajustou-se o volume com água deionizada. Após $30 \mathrm{~min}$ foi medida a absorbância a $700 \mathrm{~nm}$. A curva analítica foi ajustada 
pelo método dos mínimos quadrados e o coeficiente de correlação linear obtido foi de 0,9986 .

Para determinação do teor de fenólicos totais nos extratos de própolis foram pesados $25 \mathrm{mg}$ de cada extrato de própolis seco (hidroalcoólico ou oleoso) e dissolvidos em $25 \mathrm{~mL}$ de metanol. Desta solução foram retirados $125 \mu \mathrm{L}$ e reproduzido o procedimento descrito para as soluções padrão de ácido gálico. Cada determinação foi feita em triplicata.

\section{Quantificação de flavonóides}

Para a curva analítica foram preparadas soluções metanólicas padrão de quercetina em concentrações entre 1 a $75 \mu \mathrm{g} / \mathrm{mL}$. Em balão volumétrico de $5 \mathrm{~mL}$ misturaram-se $500 \mu \mathrm{L}$ de cada solução padrão com $250 \mu \mathrm{L}$ de uma solução $5 \% \mathrm{~m} / \mathrm{v}$ de cloreto de alumínio em metanol. Ajustou-se o volume com metanol. Esperou-se $30 \mathrm{~min}$ para realizar as medidas de absorbância em $425 \mathrm{~nm}$. O coeficiente de regressão linear obtido foi de 0,9994.

Para analisar o teor de flavonóides nos extratos de própolis hidroalcoólico ou oleoso, $500 \mu \mathrm{L}$ das soluções preparadas previamente dos extratos secos de própolis foram tratados de maneira idêntica aos padrões de quercetina.

\section{Análise de componentes principais}

Os resultados obtidos com a determinação de fenólicos totais e flavonóides nos extratos oleosos e hidroalcoólicos foram avaliados usando-se a análise multivariada. A análise estatística dos resultados provenientes dos extratos hidroalcoólicos e oleosos de própolis quanto aos teores de substâncias fenólicas e rendimentos de extração foi executada usando-se o software Statistica 6.0.

\section{Análise da atividade antibacteriana dos extratos de própolis obtidos com etanol 30, 70, 95\% v/v e óleo de canola}

A atividade antibacteriana foi avaliada através do método de difusão em ágar. Os microorganismos empregados foram os Grampositivos: Staphylococcus aureus ATCC 25923 e Listeria monocitogenes ATCC 19111 e Gram-negativos: Escherichia coli ATCC25922; Salmonella tiphimurium ATCC 14028; Pseudomonas aeruginosa ATCC 27853.

Os microrganismos foram cultivados em caldo de tripticase de soja a $37{ }^{\circ} \mathrm{C}$ por $24 \mathrm{~h}$ e após padronização foram semeados com o auxilio de swab estéril em placas de Petri contendo $15 \mathrm{~mL}$ de meio ágar tripticase de soja. Depois da absorção completa do inoculo, foram feitos poços de $7 \mathrm{~mm}$ no meio. Os extratos de própolis obtidos com soluções hidroalcoólicas 30, 70 e 95\% v/v e com óleo de canola (extração 90 dias) foram dissolvidos em etanol em uma concentração $10 \% \mathrm{~m} / \mathrm{v} .50 \mu \mathrm{L}$ das soluções dos extratos foram adicionados aos poços. Foram utilizados como controle negativo o etanol e como controle positivo o antibiótico gentamicina $(50 \mu \mathrm{g} / \mathrm{mL})$. As placas foram incubadas a $37^{\circ} \mathrm{C}$ por $24 \mathrm{~h}$. Para quantificar a atividade antibacteriana foi medido o halo de inibição do crescimento bacteriano com o auxílio de paquímetro. Todos os ensaios foram realizados em triplicata.

Análise da atividade citotóxica dos extratos de própolis obtidos com etanol 30, 70, 95\% v/v e óleo de canola

Os extratos foram avaliados quanto a sua capacidade citotóxica frente a 4 linhagens de células tumorais humanas: HL-60 (leucemia), HCT-116 (cólon), MDA/MB-435 (mama) e SF-295 (glioblastoma), através do método de $\mathrm{MTT} .{ }^{40} \mathrm{O}$ mesmo é um método rápido, sensível e barato que analisa a viabilidade e o estado metabólico da célula, baseado na conversão do sal 3-(4,5-dimetil-2-tiazol)-2,5-difenilbrometo de tetrazolium (MTT) em azul de formazan, a partir de enzimas mitocondriais presentes somente nas células metabolicamente ativas. Todas as linhagens celulares utilizadas foram mantidas em meio RPMI suplementado com $10 \%$ de soro fetal bovino, $2 \mathrm{mM}$ de glutamina e $1 \%$ de antibióticos $(100 \mathrm{U} / \mathrm{mL}$ de penicilina e 100 $\mu \mathrm{g} / \mathrm{mL}$ de estreptomicina), a $37{ }^{\circ} \mathrm{C}$, em atmosfera com $5 \%$ de $\mathrm{CO}_{2}$ e $95 \%$ de umidade

As amostras dissolvidas em dimetilsulfôxido (DMSO) puro e estéril na concentração estoque de $10 \mathrm{mg} / \mathrm{mL}$ foram diluídas seriadamente em meio RPMI $(0,09-50 \mu \mathrm{g} / \mathrm{mL})$ e adicionadas a placas de 96 poços $(100 \mu \mathrm{L} /$ poço $)$ contendo as células previamente plaqueadas. Depois de $72 \mathrm{~h}$ de incubação em estufa a $37{ }^{\circ} \mathrm{Ce} 5 \%$ de $\mathrm{CO}_{2}$, as placas foram centrifugadas, o sobrenadante aspirado e foram adicionados $150 \mu \mathrm{L}$ de MTT $10 \% \mathrm{~m} / \mathrm{v}$ por poço. Após incubação a $37^{\circ} \mathrm{C}$ por $3 \mathrm{~h}$, as placas foram novamente centrifugadas e aspiradas. $\mathrm{O}$ precipitado foi ressuspendido em $150 \mu \mathrm{L}$ de DMSO e foi feita a leitura em Espectrofotômetro de placa DTX-880, Beckman Coulter a $595 \mathrm{~nm}$. O quimioterápico doxorubicina foi usado como controle positivo.

\section{RESULTADOS E DISCUSSÃO}

\section{Comparação por ESI(-)-MS da composição química dos extratos etanólico e oleoso de própolis}

As Figuras 2, 3 e 4 mostram os ESI(-)-MS obtidos para a avaliação qualitativa do óleo de canola puro (referência), do extrato etanólico e do extrato oleoso de própolis.

Ao comparar os três ESI(-)-MS obtidos, percebeu-se que o espectro de óleo de canola puro (Figura 2), usado como referência para o extrato de própolis oleoso, apresentou poucos sinais, que correspondem aos principais ácidos graxos presentes na sua composição

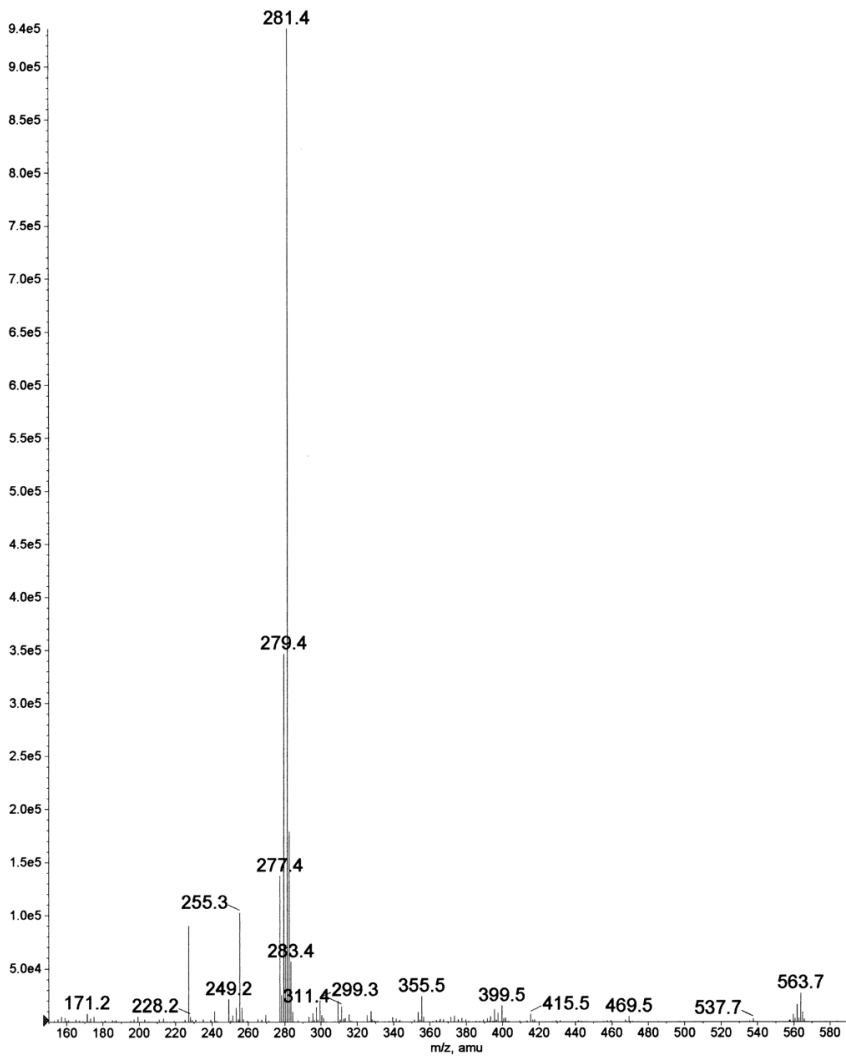

Figura 2. ESI(-)-MS do óleo de canola puro 


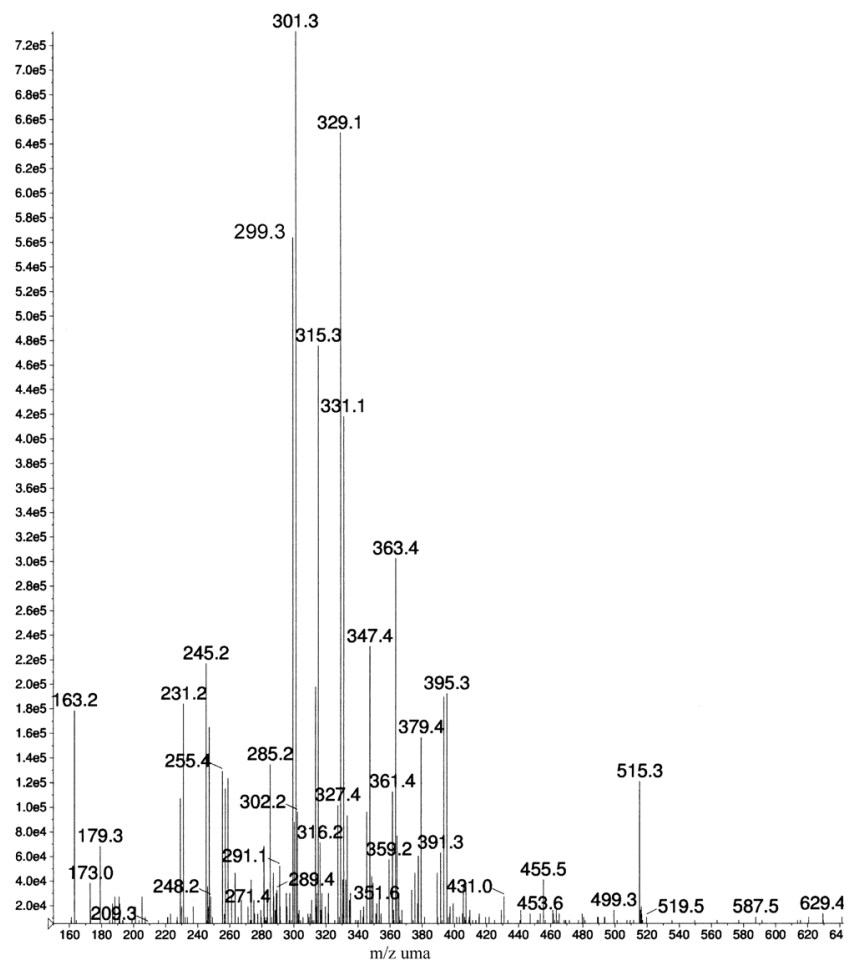

Figura 3. ESI(-)-MS do extrato da própolis obtido com etanol 95\% v/v

em $\mathrm{m} / z, 279$ e 281 (ácido oléico e linoléico). O extrato etanólico da própolis apresentou íons intensos de $m / z$ 299,3 e 301,3 (Figura 3). Segundo Sawaya e colaboradores esses íons são marcadores da própolis marrom tipo B2 do Paraná. ${ }^{22}$ Esta própolis é rica em derivados de ácidos fenólicos e apresenta características que variam entre a própolis verde encontrada nos estados de São Paulo, Minas Gerais, Mato Grosso do Sul e Paraná e a própolis marrom tipo B1 do sul do Brasil. Desta maneira, a própolis marrom tipo B2 é classificada como

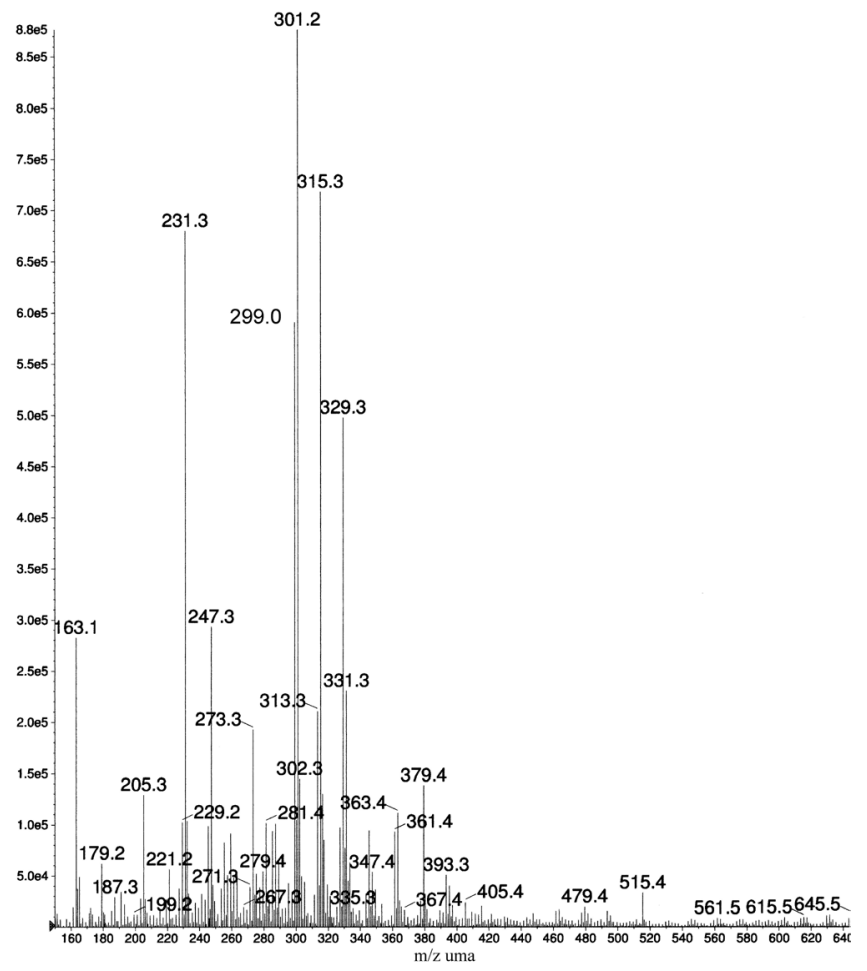

Figura 4. ESI(-)-MS do extrato da própolis obtido com óleo de canola própolis mista indicando que as resinas utilizadas pelas abelhas foram provavelmente obtidas a partir de mais de uma espécie vegetal.

O ESI(-)-MS do extrato oleoso (Figura 4) da própolis apresentou o mesmo perfil observado para o ESI(-)-MS do extrato etanólico, tendo muitos íons em comum. Neste estudo foi possível sugerir, através da comparação com padrões, a identidade de alguns íons observados no ESI-MS como a presença dos flavonóis canferida $(\mathrm{m} / z$ 299), diidrocanferida $(\mathrm{m} / \mathrm{z}, 301)$ e betuletol $(\mathrm{m} / \mathrm{z}, 329)$, os ácidos 2,2-dimetil2H-1-benzopirano-6-propenóico $(\mathrm{m} / \mathrm{z}, 229)$, p-cumárico $(\mathrm{m} / \mathrm{z}, 163)$, cafeíco ( $\mathrm{m} / \mathrm{z}, 179)$, 3-prenil-4-hidroxicinâmico $(\mathrm{m} / \mathrm{z}, 231), 3$,4-diidroxi5-prenilcinâmico ( $\mathrm{m} / \mathrm{z}, 247)$, 4-hidroxi-3(E)-(4-hidroxi-3-metil-2butenil)-5-prenilcinâmico ( $\mathrm{m} / \mathrm{z}$ 315), 3-prenil-4-diidrocinamoloxicinâmico $(\mathrm{m} / \mathrm{z}, 363)$ e dicafeoilquínico $(\mathrm{m} / \mathrm{z}, 515)$. Esses compostos estão presentes em ambos os extratos oleoso e etanólico.

No entanto, a análise realizada por ESI-MS foi qualitativa, uma vez que, devido aos efeitos de supressão iônica não se pode afirmar que a intensidade de cada íon seja proporcional à sua concentração. Deste modo, para se conhecer as quantidades em que os compostos fenólicos se encontram em ambos os extratos, os teores de fenólicos totais e flavonóides em extratos etanólicos e oleosos da própolis foram determinados pelo método espectrofotométrico.

\section{Teores de fenólicos totais e flavonóides de extratos etanólicos e oleosos de própolis}

A Tabela 1 apresenta os rendimentos e os teores de fenólicos totais e flavonóides obtidos quando a própolis foi extraída com solventes hidroalcoólicos, em diferentes composições, e com óleo de canola, por períodos de extração diferentes. Os teores de fenólicos e flavonóides foram expressos como porcentagens relativas $\mathrm{m} / \mathrm{m}$ ao extrato seco de própolis e à própolis in natura.

Para melhor comparar os extratos hidroalcoólicos e oleosos de própolis quanto às variáveis consideradas e correlacionar esses dados com o tipo de solvente e tempo de extração empregado foi feita a análise das componentes principais (ACP). O cálculo da análise de componente principal (APC) é um método exploratório que ajuda na elaboração de hipóteses gerais a partir dos dados coletados. Para a análise exploratória, é de fundamental importância entender que os scores fornecem a composição das ACPs em relação aos objetos (amostras), enquanto que os loadings fornecem essa mesma composição em relação às variáveis consideradas. No presente estudo, as amostras foram os extratos de própolis obtidos com solventes de composições diferentes e as variáveis consideradas foram V1 - solvente de extração, V2 - tempo de extração, V3 - rendimento de extração, V4 - teor de fenólicos em extrato de própolis, V5 - teor de flavonóides em extrato de própolis, V6 - teor de fenólicos em relação à própolis in natura, V7 - teor de flavonóides em relação à própolis in natura.

Entre as amostras avaliadas pela ACP (Figura 5), observou-se a formação de 3 grupos diferentes. Em torno do eixo positivo do fator 1 reuniram-se os extratos oleosos que se relacionaram pela variável tempo de extração. $\mathrm{O}$ aumento deste tempo de 10 para 90 dias ocasionou um aumento dos rendimentos e dos teores de fenólicos totais e flavonóides. No entanto, os extratos oleosos apresentaram os menores rendimentos em relação aos hidroalcoólicos. No eixo positivo do fator 2 encontramse os extratos de própolis obtidos com etanol 30 e $50 \%$ v/v. Este grupo apresentou os menores rendimentos de extração dentre as extrações hidroalcoólicas, porém os maiores teores de substâncias fenólicas no extrato seco de própolis, sendo o extrato mais rico em fenólicos o obtido com etanol $30 \%$ v/v. No quadrante negativo dos eixos X e Y encontra-se o grupo dos extratos etanólicos 70, 80, 95\% v/v e etanol absoluto. Este grupo apresentou os maiores rendimentos de extração e relacionou-se com as variáveis teor de fenólicos e flavonóides em relação à própolis bruta e ao extrato seco e solvente empregado na 
Tabela 1. Rendimentos e teores de fenólicos e flavonóides dos extratos hidroalcoólicos e oleosos ( $\mathrm{n}=3$ )

\begin{tabular}{|c|c|c|c|c|c|}
\hline Extrato & $\begin{array}{l}\text { Rendimento } \\
\text { extração }(\%)\end{array}$ & $\begin{array}{c}\text { Teor fenólicos } \\
\text { extrato seco }(\%)\end{array}$ & $\begin{array}{l}\text { Teor flavonóides } \\
\text { extrato seco }(\%)\end{array}$ & $\begin{array}{c}\text { Teor fenólicos } \\
\text { própolis bruta }(\%)\end{array}$ & $\begin{array}{c}\text { Teor flavonóides } \\
\text { própolis bruta }(\%)\end{array}$ \\
\hline 1) Etanol*30\% & 16,35 & $15,95 \pm 0,34$ & $2,77 \pm 0,04$ & $2,61 \pm 0,06$ & $0,46 \pm 0,01$ \\
\hline 2) Etanol* $50 \%$ & 30,38 & $12,01 \pm 0,20$ & $3,91 \pm 0,04$ & $3,65 \pm 0,06$ & $1,19 \pm 0,01$ \\
\hline 3) Etanol $* 70 \%$ & 54,10 & $10,96 \pm 0,02$ & $5,05 \pm 0,04$ & $5,93 \pm 0,01$ & $2,74 \pm 0,02$ \\
\hline 4) Etanol* $80 \%$ & 48,81 & $10,68 \pm 0,22$ & $4,59 \pm 0,06$ & $5,21 \pm 0,11$ & $2,24 \pm 0,02$ \\
\hline 5) Etanol $* 95 \%$ & 45,04 & $8,55 \pm 0,14$ & $4,21 \pm 0,06$ & $3,86 \pm 0,06$ & $1,90 \pm 0,02$ \\
\hline 6) Etanol* Absoluto & 37,67 & $8,77 \pm 0,04$ & $4,80 \pm 0,01$ & $3,30 \pm 0,01$ & $1,81 \pm 0,01$ \\
\hline 7) Óleo* & 4,90 & $4,68 \pm 0,33$ & $2,25 \pm 0,13$ & $0,23 \pm 0,02$ & $0,12 \pm 0,01$ \\
\hline 8) Óleo** & 9,96 & $5,94 \pm 0,10$ & $3,90 \pm 0,25$ & $0,59 \pm 0,01$ & $0,39 \pm 0,02$ \\
\hline 9) Óleo*** & 14,35 & $8,25 \pm 0,23$ & $4,22 \pm 0,01$ & $1,19 \pm 0,04$ & $0,61 \pm 0,01$ \\
\hline
\end{tabular}

Tempo de extração $={ }^{*} 10$ dias, ${ }^{* *} 30$ dias, ${ }^{* * *} 90$ dias

extração. Observou-se para este grupo que ao mudar a composição do solvente de $70 \%$ v/v a etanol absoluto ocorreu diminuição dos teores de fenólicos e flavonóides extraídos em relação à própolis bruta e dos teores de fenólicos e flavonóides no extrato seco.
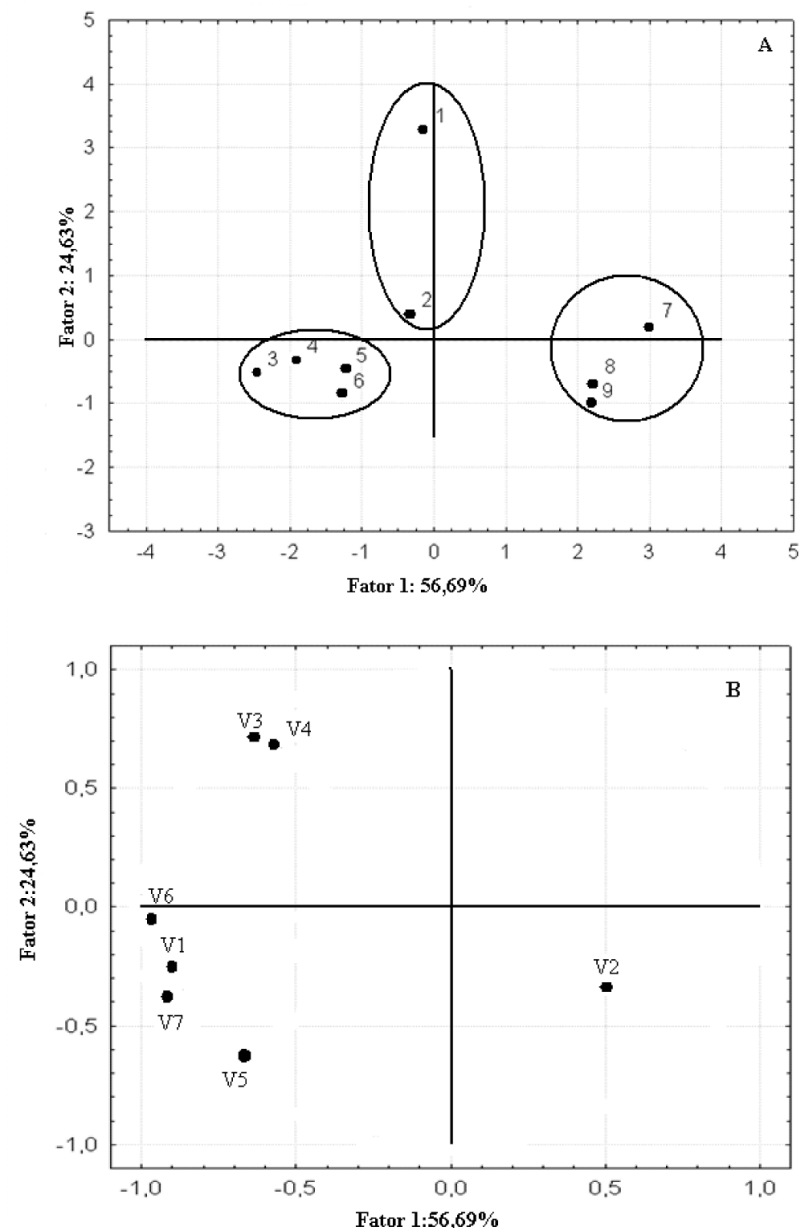

Figura 5. Análise de componentes principais para fenólicos e flavonóides totais em extratos de própolis obtidos com solventes de composições diversas: (A) amostras dos extratos de própolis (veja Tabela 1); (B) variáveis consideradas: V1 - solvente de extração; V2 - tempo de extração; V3 - rendimento de extração; V4 - teor de fenólicos em extrato de própolis; V5 - teor de flavonóides em extrato de própolis; $V 6$ - teor de fenólicos em relação à própolis in natura; V7 - teor de flavonóides em relação à própolis in natura
Wosky e Salatino reportaram uma concentração de fenólicos totais em extratos de própolis brasileira de São Paulo, Santa Catarina e Rio Grande do Sul entre 8,8 e $13,7 \%(\mathrm{~m} / \mathrm{m}) .{ }^{8}$ Cunha e colaboradores, que testaram amostras de própolis de São Paulo e Minas Gerais, encontraram valores que variaram entre 6,41 e $15,24 \%(\mathrm{~m} / \mathrm{m}){ }^{38}$ Neste trabalho, o conteúdo de fenólicos totais e flavonóides obtido nos extratos secos hidroalcoólicos variou entre 8,55 e $15,95 \%(\mathrm{~m} / \mathrm{m})$ e 2,77 a $5,05 \%(\mathrm{~m} / \mathrm{m})$, respectivamente. Portanto, os teores de fenólicos totais encontrados nesta pesquisa encontram-se de acordo com valores previamente reportados para extratos hidroalcoólicos de própolis brasileira. Wosky e Salativo encontraram teores de flavonóides nos extratos abaixo de $2,7 \% .{ }^{8}$ Todos os teores de flavonóides encontrados nos extratos de própolis da região de Prudentópolis encontraram-se acima de $2,7 \%$, com exceção do teor de flavonóides totais do extrato oleoso obtido por agitação durante 10 dias (2,25\%). Não existem relatos na literatura que contemplem estudos sobre a composição química qualitativa ou quantitativa de extratos oleosos de própolis.

\section{Atividade antimicrobiana de extratos etanólico e oleoso de própolis}

A Tabela 2 apresenta os halos de inibição obtidos para os diferentes extratos de própolis testados. Observou-se que todos os extratos hidroalcoólicos e oleoso testados apresentaram atividade contra as bactérias Gram-positivas Staphylococcus aureus e Listeria monocytogenes. Para Staphylococcus aureus, o extrato que apresentou maior atividade in vitro foi o obtido com etanol $30 \% \mathrm{v} / \mathrm{v}$, o qual apresentou também a maior concentração de compostos fenólicos. Segundo Bankova e colaboradores, ${ }^{17}$ extratos de própolis provenientes do Brasil apresentaram maior atividade contra Staphylococcus aureus que um extrato de própolis oriundo da Bulgária, o qual continha menor concentração de compostos fenólicos. Popova e colaboradores, ${ }^{41}$ ao avaliar amostras de própolis de diferentes regiões de Europa e Oriente Médio, também encontraram uma correlação negativa entre a concentração de fenólicos no extrato e a concentração inibitória mínima (CIM) ao testar extratos hidroalcoólicos de própolis contra Staphylococcus aureus, ou seja, quanto maior a concentração de fenólicos mais potente a atividade contra esta bactéria. Para Listeria monocytogenes, a maior atividade foi apresentada pelos extratos hidroalcoólico $70 \%$ v/v e oleoso.

Verificou-se também que o extrato de própolis obtido com etanol $70 \% \mathrm{v} / \mathrm{v}$ apresentou atividade contra todas as linhagens testadas, com exceção de Salmonella typhimurium. Para esta bactéria não se observou inibição do crescimento com nenhum dos extratos testados. Estes resultados reforçam relatos que mostram que extratos hidroalcoólicos de própolis possuem atividade pronunciada contra 
Tabela 2. Atividade antibacteriana de extratos hidroalcoólicos e oleoso de própolis expressa pelo halo de inibição (n=3)

\begin{tabular}{lccccc}
\hline \multirow{2}{*}{ Extrato } & & \multicolumn{3}{c}{ Halo de inibição (mm) } \\
& E. coli & S. aureus & P. aeruginosa & L. monocytogenes & S. typhimurium \\
\hline Etanol 30\% & $\mathrm{n} / \mathrm{o}^{*}$ & $11,40 \pm 0,95$ & $\mathrm{n} / \mathrm{o}$ & $5,28 \pm 0,44$ & $\mathrm{n} / \mathrm{o}$ \\
Etanol $70 \%$ & $8,82 \pm 0,53$ & $8,66 \pm 0,45$ & $2,02 \pm 0,24$ & $10,88 \pm 0,50$ & $\mathrm{n} / \mathrm{o}$ \\
Etanol 95\% & $4,86 \pm 0,42$ & $4,79 \pm 0,53$ & $\mathrm{n} / \mathrm{o}$ & $6,83 \pm 0,28$ & $\mathrm{n} / \mathrm{o}$ \\
Oleoso & $\mathrm{n} / \mathrm{o}$ & $8,05 \pm 0,57$ & $\mathrm{n} / \mathrm{o}$ & $10,63 \pm 1,00$ & $\mathrm{n} / \mathrm{o}$ \\
Controle: Gentamicina & 18,03 & 18,5 & 19,15 & 22,90 & 12,80 \\
\hline
\end{tabular}

*n/o: não observado

bactérias Gram-positivas ${ }^{2,42}$ e/ou para determinados gêneros como Streptococcus, Staphylococcus, Bacillus, Mycobacterium, porém são pouco efetivos ou inativos em relação a outros gêneros, como Pseudomonas, Escherichia, Klebsiella, Proteus e Salmonella. ${ }^{42}$

Independentemente da sua origem, a própolis sempre apresenta atividade antimicrobiana, uma vez que seu efeito bactericida e fungicida é indispensável para preservar a vida na colméia. Acredita-se que a atividade antimicrobiana da própolis se deve a efeitos sinergísticos complexos entre flavonóides, ácidos aromáticos fenólicos e seus derivados que estão presentes majoritariamente na própolis. ${ }^{2,17,43-47}$ Porém, a atividade antimicrobiana dos extratos de própolis está relacionada com o tipo de microorganismo testado e o solvente utilizado na extração. ${ }^{48}$ Assim, tem sido sugerida a determinação da CIM na avaliação da qualidade de extratos e produtos à base de própolis..$^{41,49}$

\section{Atividade citotóxica de extratos etanólicos e oleoso de própolis}

Dentre os extratos testados, o extrato oleoso mostrou possuir potencial citotóxico contra todas as linhagens celulares testadas, com $\mathrm{CI}_{50}$ variando de 0,8 a $22,6 \mu \mathrm{g} / \mathrm{mL}$ para as linhagens de HCT-116 e MDA/ MB-435, respectivamente (Tabela 3). Também este extrato foi o único que apresentou atividade contra SF-295, mostrando uma $\mathrm{CI}_{50}$ de $3.1 \mu \mathrm{g} /$ $\mathrm{mL}$. Assim como o extrato de própolis obtido com etanol $70 \% \mathrm{v} / \mathrm{v}, \mathrm{o}$ extrato oleoso revelou maior especificidade e efeito antiproliferativo contra células tumorais de cólon (HCT-116). Já os extratos de própolis obtidos com etanol 95 e 30\% v/v mostraram potencial citotóxico apenas contra carcinoma de mama (MDA/MB-435). Segundo critérios estabelecidos pelo National Cancer Institute (NCI, USA), o valor limite de $\mathrm{CI}_{50}$ para extratos com atividade citotóxica promissora é de $30 \mu \mathrm{g} / \mathrm{mL}^{50}$

Tabela 3. Atividade citotóxica in vitro de extratos de própolis frente às linhagens tumorais humanas de leucemia (HL-60), carcinoma de cólon (HCT-116), carcinoma de mama (MDA/MB-435) e glioblastoma (SF-295)

\begin{tabular}{lcccc}
\hline \multirow{2}{*}{ Extrato } & \multicolumn{4}{c}{$\mathrm{CI}_{50}(\mu \mathrm{g} / \mathrm{mL})^{*}$} \\
& HL-60 & HCT-116 & MDA/MB-435 & SF-295 \\
\hline Etanol 30\% & $>50$ & $>50$ & $26,0 \pm 6,2$ & $>50$ \\
Etanol 70\% & $4,8 \pm 1,1$ & $0,9 \pm 0,5$ & $27,2 \pm 5,6$ & $>50$ \\
Etanol 95\% & $>50$ & $>50$ & $35,3 \pm 9,1$ & $>50$ \\
Oleoso & $15,7 \pm 4,7$ & $0,8 \pm 0,1$ & $22,6 \pm 5,1$ & $3,1 \pm 1,3$ \\
\hline
\end{tabular}

*Valores originados de experimentos independentes $(n=2)$ e apresentados como $\mathrm{CI}_{50}$ obtidos por regressão não-linear \pm desvio padrão.

\section{CONCLUSÕES}

ESI(-)-MS mostrou composição química qualitativa dos extratos oleosos e hidroalcoólicos de própolis bastante similar, sendo possível identificar vários ácidos fenólicos e flavonóides presentes em ambos os extratos. A extração com óleo vegetal apresentou, porém, rendimento inferior e menores teores de substâncias fenólicas. Mesmo utilizando-se períodos de extração superiores com óleo, não foi possível obter eficiência comparável à extração hidroalcoólica.

Os teores de fenólicos totais em relação ao extrato seco foram maiores para o extrato obtido com etanol $30 \%$ v/v, diminuindo à medida que se aumentou a proporção de etanol no solvente extrator. O extrato obtido com etanol $70 \% \mathrm{v} / \mathrm{v}$ apresentou o maior rendimento e também o maior teor de flavonóides. Portanto, em relação à própolis in natura, a extração com etanol $70 \%$ apresentou as maiores porcentagens de extração de fenólicos e flavonóides.

A partir dos testes antibacterianos realizados verificou-se que o extrato oleoso apresentou atividade contra bactérias Gram-positivas Staphylococcus aureus e Listeria monocytogenes, seguindo o mesmo comportamento observado por outros pesquisadores para os hidroalcoólicos de própolis.

Nos testes de atividade citotóxica o extrato oleoso de própolis mostrou-se promissor contra todas as linhagens de células tumorais testadas, revelando maior especificidade contra aquelas de cólon e glioblastoma. Pode-se concluir que o óleo vegetal empregado foi capaz de extrair substâncias bioativas da própolis, responsáveis pelas atividades antibacteriana e citotóxica observadas.

Os resultados obtidos indicaram a viabilidade da extração da própolis com óleo vegetal, mas também a necessidade de aprimorar a formulação e o processo de extração para obter rendimentos e teores maiores de extração das substâncias fenólicas bioativas em tempos menores. No Laboratório de Pesquisa em Química Orgânica e Tecnologia da UNICENTRO já vêm sendo desenvolvidas pesquisas com esse objetivo. Também se faz necessário o estudo químico e farmacológico mais detalhado do extrato oleoso para poder identificar substâncias responsáveis pelas atividades observadas.

\section{AGRADECIMENTOS}

À Fundação Araucária pelo suporte financeiro aos projetos 10908/ Programa Primeiros Projetos/2006 e 7102/Programa Paraná Inovação Fase I-2004 e Fase II-2006. D. Finger e E. M. Schmidt agradecem à Fundação Araucária e à UNICENTRO, respectivamente, pelas bolsas de Iniciação Científica concedidas. M. N. Eberlin e A. F. W. Sawaya agradecem à FAPESP e ao CNPq pelo apoio financeiro.

\section{REFERÊNCIAS}

1. Ghisalberti, E. L.; Bee world 1979, 60, 59.

2. Marcucci, M. C.; Apidologie 1995, 26, 83.

3. Pereira, A. S.; Seixas, F. R. M. S.; Aquino Neto, F. R.; Quim. Nova 2002, 25,321

4. http://www.apacame.org.br/mensagemdoce/58/artigo.htm, acessada em Julho 2007. 
5. Park, Y. K.; Alencar, S. M.; Scamparini, A. R. P.; Aguiar, C. L.; Ciênc. rural 2002, 32, 997.

6. Castro, M. L.; Cury, J. A.; Rosalen, P. L.; Alencar, S. M.; Ikegaki, M.; Duarte, S.; Koo, H.; Quim. Nova 2007, 30, 1512.

7. http://www.bichoonline.com.br/artigos/apa0007.htm, acessada em Julho 2006.

8. Woisky, R. G.; Salatino, A.; J. Apic. Res. 1998, 37, 99.

9. http://www.apacame.org.br/mensagemdoce/70/artigo2.htm, acessada em Julho 2007.

10. Hamada, S.; Intani, S.; Miyake, T.; Br PI 9203327-A, 1993.

11. Kusztra, E. J.; Br PI 8405979, 1986.

12. Itice, N. T.; Br PI $9802777-8 A, 2000$.

13. Itice, N. T.; Br PI 9705316-3A, 2001

14. Hayashi, N.; Br PI 0002320-5A, 2002.

15. Ie, C.; Br PI 0202728-3A, 2004.

16. Bankova, V.; Kraskeva, G. B.; Sforcin, J. M.; Frete, X.; Kujumgiev, A.; Rodella, R. M.; Popov, S.; Z. Naturforsch., C: J. Biosci. 1999, 54, 401.

17. Bankova, V.; Kraskeva, G. B.; Popov, S.; Sforcin, J. M.; Funari, S. R. C.; Apidologie 1998, 29, 361.

18. Bankova, V.; Christov, R.; Kujumgiev, A.; Marcucci, M. C.; Popov, S.; Z. Naturforsch., C: J. Biosci. 1995, 50, 167.

19. Markham, K. R.; Mitchell, K. A.; Wilkins, A. L.; Daldy, J. A.; Lu, Y.; Phytochemistry 1996, 42, 205.

20. http://www.apacame.org.br/mensagemdoce/67/artigo.htm, acessada em Julho 2007.

21. Martos, I.; Cossentini, M.; Ferreres, F.; Tomás-Barberán, F. A.; J. Agric. Food Chem. 1997, 45, 2824.

22. Sawaya A. C. H. F.; Tomazela, D. M.; Cunha, I. B. S.; Bankova, V. S.; Marcucci, M. C.; Custodio, A. R.; Eberlin, M. N.; Analyst 2004, 129, 739.

23. Sawaya, A. C. H. F.; Cunha, I. B. S.; Marcucci, M. C.; Rodrigues, R. F. O.; Eberlin, M. N.; Apidologie 2006, 37, 398.

24. Sawaya, A. C. H. F.; Cunha, I. B. S.; Marcucci, M. C.; Aidar, D. S.; Silva, E. C. A.; Carvalho, C. A. L.; Eberlin, M. N.; Apidologie 2007, 38, 93.

25. Catharino, R. R.; Cunha, I. B. S.; Fogaça, A. O.; Facco, E. M. P.; Godoy, H. T.; Daudt, C. E.; Eberlin, M. N.; Sawaya, A. C. H. F.; J. Mass Spectrom. 2006, 41, 185.

26. Hughey, C. A.; Rodgers, R. P.; Marshall, A. G.; Anal. Chem. 2002, 74, 4145 .

27. Mauri, P.; Minaggio, M.; Simonetti, P.; Gardana, C.; Pietta, P.; Rapid Commun. Mass Spectrom. 2002, 16, 743.
28. Mauri, P.; Pietta, P.; J. Pharm. Biomed. Anal. 2000, 23, 61.

29. He, X.; J. Chromatogr. 2000, 880, 203.

30. Crotti, A. E. M.; Vessecchi, R.; Lopes, J. L. C.; Lopes, N. P.; Quim. Nova 2006, 29, 287.

31. Ardrey, B.; Liquid Chromatography Mass Spectrometry: an introduction, $1^{\text {st }}$ ed., Wiley: West Sussex, 2003.

32. Soares, S. E.; Rev. Nutr. 2002, 15, 71.

33. Sousa, C. M. M.; Rocha e Silva, H.; Vieira-Jr, G. M.; Ayres, M. C. C.; da Costa, C. L. S.; Araújo, D. S.; Cavalcante, L. C. D.; Barros, E. D. S.; Araújo, P. B. M.; Brandão, M. S.; Chaves, M. H.; Quim. Nova 2007, 30, 351.

34. Folin, O.; Ciocalteau, V.; J. Biol. Chem. 1927, 27, 627.

35. Malacrida, C. R.; Motta, S.; Ciênc. Tecnol. Aliment. 2005, 25, 659.

36. de Lima, V. L. A. G.; Mélo, E. A.; Lima, D. E. S.; Sci. agric. 2002, 59, 447.

37. de Lima, V. L. A. G.; Mélo, E. A.; Maciel, M. I. S.; Silva, G. S. B.; Lima, D. E. S.; Rev. Nutr. 2004, 17, 53

38. Cunha, I. B. S.; Sawaya, A. C. H. F.; Caetano, F. M.; Shimizu, M. T.; Marcucci, M. C.; Drezza, F. T.; Povia, G. S.; Carvalho, P. O.; J. Braz. Chem. Soc. 2004, 15, 964.

39. http://www.apacame.org.br/mensagemdoce/46/artigo.htm, acessada em Junho 2007.

40. Mosman, T.; J. Immunol. Methods 1983, 65, 55.

41. Popova, M. P.; Bankova, V. S.; Bogdanov, S.; Tsvetkova, I.; Naydenski, C.; Marcazzan, G. L.; Sabatini, A. G.; Apidologie 2007, 38, 306.

42. Bonvehí, J. S.; Coll, F. V. V.; Z. Naturforsch., C: J. Biosci. 1994, 49 , 712.

43. Sawaya, A. C. H. F.; Souza, K. S.; Marcucci, M. C.; Cunha, I. B. S.; Shimizu, M. T.; Braz. J. Microbiol. 2004, 35, 104.

44. Bianchini. L.; Bedendo, I. P.; Sci. agric. 1998, 55, 144.

45. Grange, J. M.; Davey, R. W.; J. R. Soc. Med. 1990, 83, 159.

46. Mazzuco, H.; Silva, R. D. M.; Berchieri Jr., A.; Oliveira, E.; Sci. agric. 1996, 53,1 .

47. Bankova, V.; Christov, R.; Popov, S.; Marcucci, M. C.; Tsvetkova, I.; Kujumgiev, A.; Fitoterapia 1999, 70, 190.

48. Tosi, B.; Donini, A.; Bruni, A.; Phytother. Res. 1996, 10, 335.

49. Menezes, H.; Bacci Jr., M.; Oliveira, S. D.; Pagnocca, F. C.; Apidologie 1997, 28, 71 .

50. Costa-Lotufo, L. V.; Khan, M. T. H.; Ather, A.; Wilke, D. V.; Jimenez, P. C.; Pessoa, C.; Moraes, M. E. A.; Moraes, M. O.; J. Ethnopharmacol. 2005, 99, 21 